\title{
Atomic Spectroscopy . \\ Depth Profiling at a Steel-aluminum Interface Using Slow-flow Direct Current Glow Discharge Mass Spectrometry
}

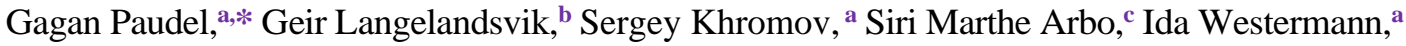 \\ Hans Jørgen Roven, ${ }^{\text {a }}$ and Marisa Di Sabatino ${ }^{\text {a }}$ \\ ${ }^{a}$ Department of Materials Science and Engineering, Norwegian University of Science and Technology, 7491 Trondheim, Norway \\ ${ }^{\mathrm{b}}$ Department of Materials and Nanotechnology, SINTEF Industry, 7491 Trondheim, Norway \\ ${ }^{c}$ Department of Materials and Technology, SINTEF Manufacturing AS, 2831 Raufoss, Norway
}

Received: June 16, 2021; Revised: November 16, 2021; Accepted: November 17, 2021; Available online: Dec 03, 2021.

\section{DOI: $10.46770 / A S .2021 .607$}

ABSTRACT: Direct current glow discharge mass spectrometry (dc-GDMS), which relies on sector field mass analyzers, is not commonly used for depth profiling applications because of its slow data acquisition. Nevertheless, dc-GDMS has good reproducibility and low limits of detection, which are analytical features that are encouraging for investigating the potential of dc-GDMS for depth profiling applications. In this work, the diffusion of traces of chromium and nickel was profiled at the interface of a steel-aluminum bilayer using a new sensitive dc-GDMS instrument. The depth profile of the non-treated sample was compared with that of a heat-treated specimen at $400^{\circ} \mathrm{C}$ for $30 \mathrm{~min}$. Scanning electron micrographs, energy dispersive X-ray spectroscopy (EDS), and electron probe microanalysis (EPMA) were used to study the diffusion process. The results of the study show that both chromium and nickel are enriched at the steel-aluminum interface, with higher concentrations of both elements for the heat-treated specimen. Two peaks for both chromium and nickel were clearly present at the interface, with a high concentration of chromium in the aluminum layer. This observation is likely a consequence of elemental diffusion from the interface towards the aluminum layer. The presence of the third layer, steel beneath the aluminum layer, might also have contributed to this observation.

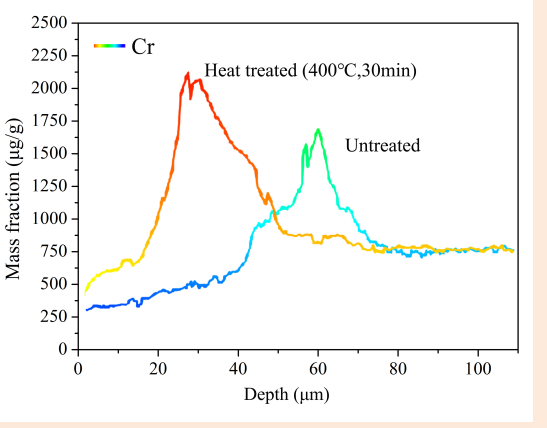

\section{INTRODUCTION}

The manufacturing of advanced materials with desirable mechanical properties is important for solving some of today's challenges, such as excessive carbon dioxide emissions. Steel and aluminum-based alloys are among the most common metals used worldwide for automotive, aviation, and marine applications. While steel offers the advantages of high strength and low cost, aluminum alloys are lightweight and are corrosion resistant. One way to reduce carbon dioxide emissions is by using lightweight materials in automotive components. Therefore, joining steel to aluminum in these structures can improve mechanical properties while reducing fuel consumption. Thus, research is underway to understand how the manufacturing of metal composites can be improved. ${ }^{1}$ The manufacturing process used during the joining process has a major influence on the strength of the final joint ${ }^{2}$ and the performance of the final processed material. During the bonding process it is possible to form intermetallic layers with mechanical properties different from those of the base materials. For instance, the intermetallic layer thickness, and type of phases present, can influence the strength of the final joint. ${ }^{3}$ The chemical composition of the base materials has been found to influence the formation of intermetallic phases along the joint interface. ${ }^{4,5}$ However, the exact mechanism of phase formation and the influence of each element are not well understood. Hence, there is a need to develop profiling techniques that monitor the changes in the concentration of alloying elements near the interface to understand elemental diffusion. 
Several analytical techniques are available for the depth profiling of materials, including but not limited to secondary ion mass spectrometry (SIMS), laser ablation-inductively coupled plasma mass spectrometry (LA-ICPMS), glow discharge optical emission spectroscopy (GDOES), and glow discharge mass spectrometry (GDMS). In this study, we focus on GDMS-related depth profiling and present the features and limitations of various types of GDMS instruments. A popular instrument for depth profiling is a GDMS instrument with a pulsed-radio frequency source coupled to a time-of-flight (TOF) mass analyzer. Some of the particularly useful features of this instrument include acquisition of full spectra at a high speed, time-gated detection, ${ }^{6}$ separation of various glow discharge regions, ${ }^{7}$ reduction of interference and good signal to noise ratio, ${ }^{8}$ direct analysis of non-conductive materials, ${ }^{9}$ and the possibility of analysis of thermosensitive samples. ${ }^{10}$ Furthermore, the use of the pulsed mode increases the instantaneous power while reducing the heat generation during the sputtering process, thereby increasing the signal intensity. ${ }^{11}$ This instrument type was successfully used for the profiling of ion implants in silicon substrates ${ }^{12}$ and for the profiling of layered materials $\left(\mathrm{Nb} / \mathrm{Al}^{13}, \mathrm{Nb}_{1} / \mathrm{Al}_{1-\mathrm{x}}-\mathrm{Co}_{\mathrm{x}}{ }^{14}\right.$ and $\mathrm{Si} / \mathrm{Co}^{15}$ ) of various thicknesses. Furthermore, applications of this instrument type in solar cell research for the profiling of silicon thin films ${ }^{16}$ and cadmium telluride (CdTe) solar cells ${ }^{17}$ have been investigated. Another notable feature of this instrument is the ability to generate molecular ions, which allows for the characterization of polymer-based composite materials. ${ }^{18}$ Plasma profiling time-of-flight mass spectrometry (PP-TOFMS) is one of these instrument types introduced by the HORIBA Jobin-Yvon (France) company in 2014. This instrument allows the characterization of flat-shaped samples in either continuous or pulsed radiofrequency (RF) mode. Likewise, the Lumas 30 (Lumex Ltd., Russia) instrument introduced in 2007 uses hollow cathode geometry for sample characterization in pulsed direct current mode using a TOF analyzer. In 2014, Bodnar et al. reported the depth profiling measurement of fluorine in a fluorine-doped potassium titanyl phosphate crystal material. ${ }^{19}$ Another recent study from the same group reported depth profiling of a conductive metal coating on a silicon substrate as well as semiconductive and multi-layer nonconductive coatings on glass substrates. ${ }^{20}$

TOF instruments have a limit of detection of concentration in $\mu \mathrm{g} / \mathrm{g}$, which is two to three orders of magnitude lower than sector-field instruments. Hence, the sector-field instruments are more suitable when detecting low levels of impurities is important, for instance in solar cell research. Sector-field instruments, such as the Element GD (Thermo Electron now Thermo Fischer Scientific, Germany, 2005) and VG 9000 (VG Elemental, UK, production discontinued), are currently the most common GDMS instruments in research institutes, universities and contract laboratories. These instruments are often referred to as "fast-flow" and "slow-flow" instruments respectively, which are named after the discharge gas flow rates. It is worth mentioning some notable research works that use these instruments.

Using fast-flow GDMS, Su et al. demonstrated the depth profiling of major and trace elements in nickel-based superalloys. ${ }^{21}$ Di Sabatino et al. estimated the limits of detection of impurities in silicon used for solar cells using matrix-specific relative sensitivity factors (RSFs). ${ }^{22,23}$ The profiling of impurities in solar cell silicon at the $\mathrm{ng} / \mathrm{g}$ level was carried out as well. ${ }^{24}$ Likewise, other notable study from the same group is measurement of copper diffusion in silicon substrate. ${ }^{25}$

For quality control of the final silicon wafers, the impurity content of processed ingots is routinely assessed. In such studies, the distribution of dopants is investigated in entire silicon ingots, which can be of several meters in height. As the depth profiling of such large ingots is not possible, the ingots are systematically sampled at various locations of the ingot where bulk analysis of each slice is performed. The bulk measurements of dopants of several samples obtained from different locations were combined, resembling a depth profile. ${ }^{26-28}$

Notable work has been carried out using the VG 9000 for the characterization of coated and layered materials, such as platinum-aluminide coatings on a nickel base ${ }^{29}$ and hafnium-doped aluminide coatings. ${ }^{30}$ As VG 9000 production was discontinued in 2005 , there is a need to understand the depth-profiling capabilities of similar slow-flow instruments that are currently available, such as the Astrum GDMS (Nu Instrument, UK) and the AutoConcept GD 90 (Mass Spectrometry Instruments, UK). Despite their introduction in 2010 and 2008, respectively, there is limited information available in the literature demonstrating the depth-profiling capabilities of these two instruments. In this work, nickel and chromium present in the steel-aluminum bilayer were profiled using an Astrum GDMS instrument. This work aims to improve the understanding of the diffusion of trace elements that are involved in the formation of intermetallic layers.

\section{QUANTIFICATION OF IMPURITIES}

For this work, the determination of the concentration of chromium and nickel present in the bilayer material was performed using a certified aluminum reference material. At present, it is not possible to correct for differences in the sputtering rates of the steel and aluminum matrices. Therefore, a compromise was made by assuming that a steel layer was present on the top of the aluminum layer. RSFs were applied to the depth profiles using several certified aluminum reference materials to calibrate the data. Eq. 1 was used to determine the concentration of impurity elements.

$$
\mathrm{C}_{\mathrm{X}^{\prime} / \mathrm{Al}}=\frac{\mathrm{I}_{\mathrm{Xi}}}{\mathrm{I}_{\mathrm{Ali}}} \times \frac{\mathrm{A}_{\mathrm{Ali}}}{\mathrm{A}_{\mathrm{Xi}}} \times \mathrm{RSF}_{\mathrm{X} / \mathrm{Al}}
$$


where $C_{\mathrm{X}^{\prime} / \mathrm{Al}}$ is the mass fraction of impurity element/isotope $\mathrm{X}^{\prime}$ present in the aluminum matrix, $I_{\mathrm{Xi}}$ and $I_{\mathrm{Ali}}$ are the intensities of the impurity analyte and aluminum, respectively, $A$ xi and $A_{\text {Ali }}$ are the natural isotope abundances of the impurity analyte and aluminum, respectively, and $\mathrm{RSF}_{\mathrm{X} / \mathrm{Al}}$ represents the relative sensitivity factor of a specific analyte, $\mathrm{X}$, present in an aluminum matrix. RSFs are estimated mathematically as the inverse of the slope of the calibration curve IBRX/Al versus mass fraction $\mathrm{Cx} / \mathrm{Al}$ (Eq. 2). The ion beam ratio IBR $\mathrm{X} / \mathrm{Al}$ was generated by measuring the materials.

$$
\mathrm{RSF}_{\mathrm{X} / \mathrm{Al}}=\frac{C_{\mathrm{X} / \mathrm{Al}}}{\mathrm{IBR}_{\mathrm{X} / \mathrm{Al}}}
$$

\section{MATERIALS AND METHODS}

Sample preparation. The steel-aluminum joints were prepared by a cold roll bonding procedure using $99.8 \mathrm{wt} \%$ AA1080 grade aluminum and $355 \mathrm{MC}$ E grade steel (with matrix composition of $0.07 \mathrm{wt} \% \mathrm{C}, 0.01 \mathrm{wt} \% \mathrm{Si}, 0.62 \mathrm{wt} \% \mathrm{Mn}, 0.05 \mathrm{wt} \% \mathrm{Al}, 0.03$ wt $\% \mathrm{Cr}$ and $0.03 \mathrm{wt} \% \mathrm{Ni}$ ) as base materials. The sample materials were cut to the desired dimensions of $120 \mathrm{~mm} \times 15$ $\mathrm{mm}$. The initial thicknesses of the aluminum and steel before rolling were $0.4 \mathrm{~mm}$ and $1 \mathrm{~mm}$, respectively. Prior to this, the steel sample was rolled at room temperature from $3 \mathrm{~mm}$ to $1 \mathrm{~mm}$, followed by annealing at $750{ }^{\circ} \mathrm{C}$ for $4 \mathrm{~h}$ in a furnace under an argon atmosphere to soften the steel and prevent oxidation. The total thickness reduction of the rolled composite material was in the range of $60 \%-65 \%$. It should be noted that the steel layer was grinded. A detailed procedure for the sample production can be found in literature ${ }^{3}$.

The sample materials were cleaned with acetone and the surface was prepared by manual brushing with a $0.3 \mathrm{~mm}$ steel-wire brush followed by blowing clean with compressed air. The purpose of the brushing step was to generate a rough surface to promote bonding. The specimens were stacked together in the sequence steel-aluminum-steel and fastened with aluminum rivets at each end to prevent lateral movement during rolling. To further promote bonding, the stacked material was preheated in a furnace for $10 \mathrm{~min}$ at $185^{\circ} \mathrm{C}$ until the desired rolling temperature of $150^{\circ} \mathrm{C}$ was reached. After preheating, the samples were removed from the furnace and rolled using a high rolling mill with a roll diameter of $205 \mathrm{~mm}$ and a rolling speed of approximately $10 \mathrm{rpm}$. After rolling, the material was immediately submerged in water.

The rolled steel-aluminum-steel composite material was cut by $\mathrm{SiC}$ cutoff blade to produce samples with dimensions of $30 \mathrm{~mm}$ $\times 25 \mathrm{~mm}$ to fit the GDMS flat sample holder. One set of samples was heated at $400{ }^{\circ} \mathrm{C}$ for $30 \mathrm{~min}$. The composite material was manually grinded to reduce the thickness of the steel layer using a series of silicon carbide papers to obtain a mirror finish. Finally, the specimen was cleaned with ethanol and dried in air.

GDMS method. Before analyzing the samples, the instrument (Astrum, $\mathrm{Nu}$ Instruments, UK) was tuned and calibrated for different masses with tantalum: ${ }^{12} \mathrm{C}^{+},\left({ }^{40} \mathrm{Ar}\right)^{2+},{ }^{36} \mathrm{Ar}^{+},\left({ }^{40} \mathrm{Ar}\right) 2^{+}$, $\left({ }^{40} \mathrm{Ar}\right) 3^{+},{ }^{181} \mathrm{Ta}^{+},{ }^{181} \mathrm{Ta}^{+}{ }^{40} \mathrm{Ar}^{+}$at discharge conditions of $2 \mathrm{~mA}$ and $1 \mathrm{kV}$. The ${ }^{181} \mathrm{Ta}$ signal intensity of $1.4 \times 10^{-9} \mathrm{~A}$ was observed with a magnet scan at a resolution power of approximately 4000 (M/ $\Delta \mathrm{M}, 10 \%$ of peak height approach). The glow discharge cell of the instrument was cryogenically cooled, and $99.9999 \%$ argon was used as the discharge gas. For GDMS, the size of the orifice of the tantalum front plate used in the flat sample holder determines the lateral resolution. For this study, an orifice with a diameter of $10 \mathrm{~mm}$ was used, which contributed to the lateral size of crater profiles of approximately $10 \mathrm{~mm}$. It is important to mention that for GDMS-related depth profiling, the edge of the crater is also analyzed. For ${ }^{56} \mathrm{Fe}$ and ${ }^{27} \mathrm{Al}$, an integration time of $160 \mathrm{~ms}$ was used. These elements were detected using a Faraday cup. For ${ }^{52} \mathrm{Cr}$ and ${ }^{60} \mathrm{Ni}$, an integration time of $80 \mathrm{~ms}$ was used. These elements were detected using an electron multiplier. The most abundant isotope of nickel, ${ }^{58} \mathrm{Ni}$, suffers from monoatomic interference due to ${ }^{58} \mathrm{Fe}$. Therefore, ${ }^{60} \mathrm{Ni}$ was chosen as the isotope for this study. The measurements were performed at a resolution power of approximately $4000(\mathrm{M} / \Delta \mathrm{M}, 10 \%$ of the peak height approach). For depth profiling study, the composite and base materials were subjected to glow discharge setting of 5 $\mathrm{mA}, 0.75 \mathrm{kV}$ in a constant current mode. The current and voltage readback values were largely stable during the analysis period. The GDMS craters were measured mechanically using a profilometer (MarSurf M 400, Mahr GmbH, Göttingen, Germany) immediately after the sputtering event.

Other complimentary techniques. After GDMS analysis, the composite materials were cut in half and immobilized on a substrate using epoxy resin. The samples were prepared by standard metallographic procedures, involving grinding on silicon carbide discs, and polishing on cloth with diamond paste until a deformation-free mirror finish was obtained. The craters were further investigated using an optical microscope (Zeiss Axiovert, Carl Zeiss AG, Jena, Germany). Scanning electron microscope (SEM) images were taken using a Zeiss Supra 55-VP (Jena, Germany) and energy-dispersive X-ray spectroscopy (EDS) standardless analysis using an EDAX Octane PRO-A detector (Ametek, USA). Elemental analysis was carried out using JEOL JXA-8500F electron probe microanalyzer (EPMA) with an electron beam size of $1 \mu \mathrm{m}$. For quantitative wavelength-dispersive X-ray spectroscopy (WDS) in EPMA, a pure standard of $100 \%$ aluminum and one steel standard SRM663 were used. The composition of the steel standard was $95.01 \mathrm{wt} \%$ iron, $0.24 \mathrm{wt} \%$ aluminum, $1.31 \mathrm{wt} \%$ chromium and $0.32 \mathrm{wt} \%$ nickel. 


\section{RESULTS AND DISCUSSION}

Crater shape. The prerequisite for depth profiling applications is uniform sputtering of the sample. Therefore, after completion of the sputtering event, it is advisable to check the crater shape. Ideally, the crater bottom should be flat with a minimum edge effect and a crater wall that is perpendicular to the crater bottom. The evolution of the crater profile with changes in the glow discharge condition can be found in the literature. ${ }^{31}$ The crater shape can also vary from one matrix specimen to another. Therefore, as a first step we determined the discharge conditions that lead to the optimum crater shapes for the base materials. Figs. S1A and S1B represent the crater shape for aluminum and steel base materials, respectively, after sputtering for $1.5 \mathrm{~h}$. The sputtering rate was $129.4 \mathrm{~nm} / \mathrm{min}$ and $79 \mathrm{~nm} / \mathrm{min}$ for aluminum and steel, respectively, at discharge condition of $5 \mathrm{~mA}$ and 0.75 $\mathrm{kV}$. The argon flow of $0.69 \mathrm{ml} / \mathrm{min}$ and $0.48 \mathrm{ml} / \mathrm{min}$ were used for obtaining the discharge condition for aluminum and steel base materials, respectively.

It is important to mention that the shape of the steel crater profile is not ideal. However, as the idea was to profile the steel-aluminum joint, a compromise had to be made. Furthermore, any change in the glow discharge condition during the sputtering process (with the aim of obtaining the optimum crater) would influence the signal stability. Additionally, the specimen analysis brought other challenges such as matrix-specific calibration, the lack of direct access to aluminum (stacked between two steel layers), and the slow sputtering rate of Astrum GDMS instrument. Hence, the steel layer was manually grinded, where the composite material was assumed to be steel on top of the aluminum rather than the steel-aluminum bilayer. Therefore, only one side of the composite material was characterized.

For simplicity, the heat-treated composite material is referred to as the "treated" sample while the non-heat-treated material is referred to as the "untreated" sample. The crater shapes of the untreated and treated samples are presented in Fig. 1, where the

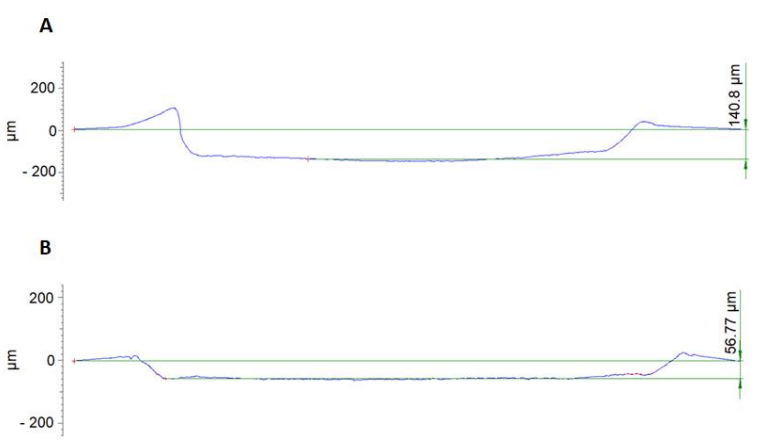

Fig. 1 The crater profile of untreated (A) and treated (B) samples after sputtering for $16 \mathrm{~h} 20 \mathrm{~min}$ and $8.5 \mathrm{~h}$ at glow discharge condition of $5 \mathrm{~mA}$, $0.75 \mathrm{kV}$ using argon flow rates of $0.85 \mathrm{ml} / \mathrm{min}$ and $0.83 \mathrm{ml} / \mathrm{min}$ respectively.

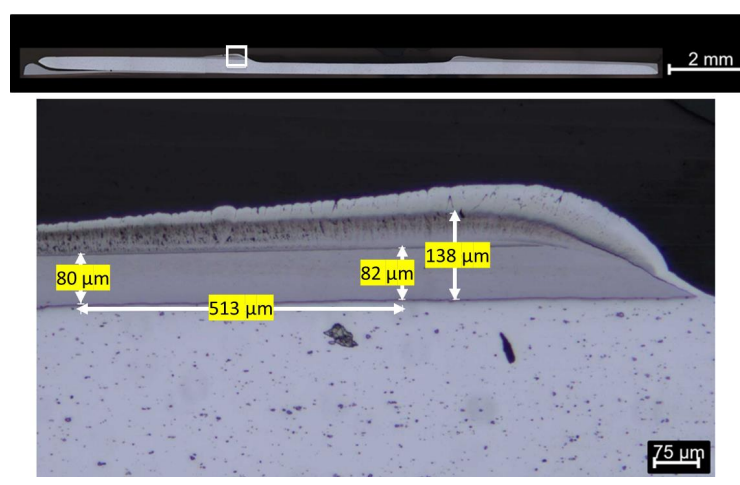

Fig. 2 The lateral view of the untreated sample cut at the crater after GDMS sputtering. Optical microscopy images of the crater at low resolution (top) with a shaded area around which a high- resolution image is taken (bottom).

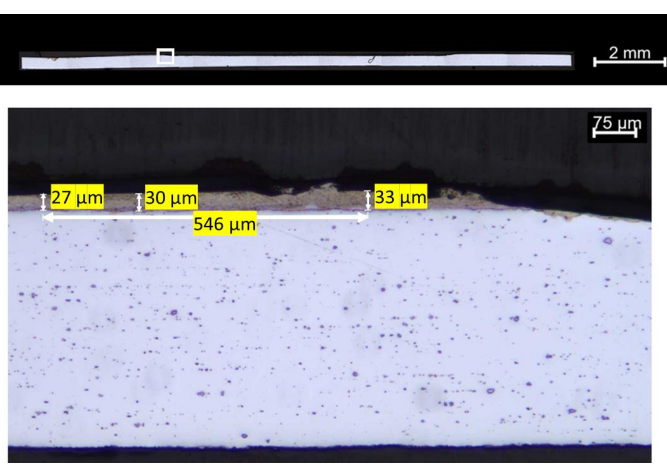

Fig. 3 The lateral view of the treated sample cut at the crater after GDMS sputtering. Optical microscopy images of the crater at low resolution (top) with a shaded area around which a high-resolution image is taken (bottom).

untreated sample was sputtered to a greater depth compared to the treated sample. The total sputtering time for untreated and treated samples were $16 \mathrm{~h} 20 \mathrm{~min}$ and $8 \mathrm{~h} 30 \mathrm{~min}$ corresponding to sputtering rates of $143.9 \mathrm{~nm} / \mathrm{min}$ and $111.3 \mathrm{~nm} / \mathrm{min}$, respectively. The differences in sputtering depth and time are related to inconsistency in the steel layer thickness in the samples. The untreated sample (Fig. 2) had a thicker steel layer compared to the treated sample (Fig. 3). The optical microscopy images shown in Figs. 2 and 3 were taken after cutting the sample at the crater, followed by investigation of the lateral sections of the samples. Furthermore, the redisposition of steel and aluminum layers outside the crater was clearer for the untreated sample compared with the treated sample.

RSFs determination. In this work, the reported concentration of impurities is based on the RSFs determined using certified aluminum reference materials. Using Eq. 2, these values are determined as the inverse of the slopes obtained from the linear plots presented in Fig. 4 for chromium and nickel. The RSFs were calculated at discharge conditions of $5 \mathrm{~mA}, 0.75 \mathrm{kV}$. The RSFs values for ${ }^{52} \mathrm{Cr}$ and ${ }^{60} \mathrm{Ni}$ in aluminum were found to be 0.91 and 1.25 , respectively. 
A

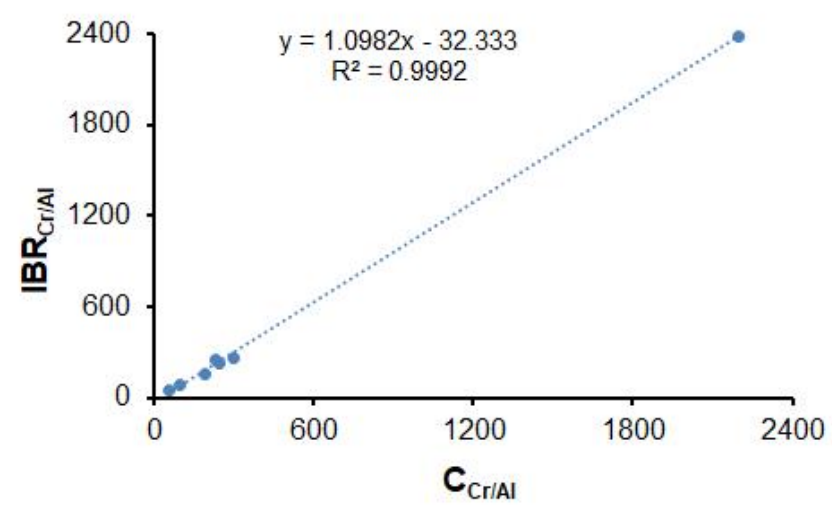

B

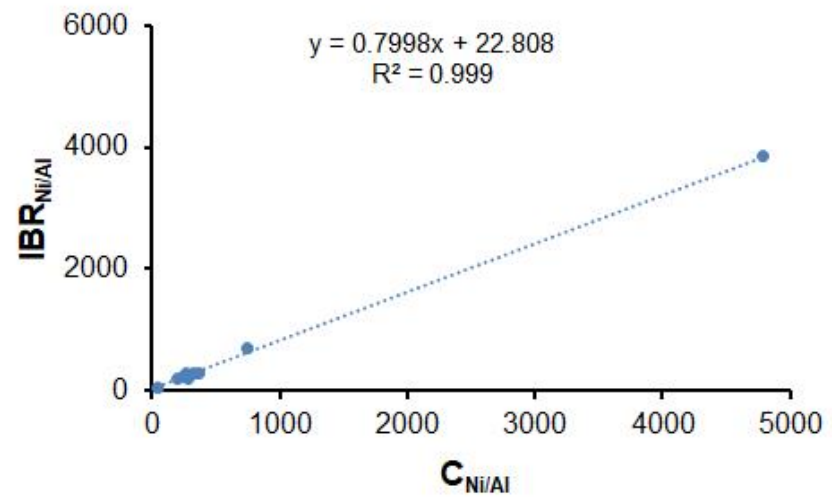

Fig. 4 Abundance-corrected ion beam ratio curves as a function of mass fraction for chromium (A) and nickel (B) based on several certified aluminum reference materials.

Depth profiling. The GDMS bulk measurements of the aluminum and steel base materials are presented in Table S1. The same discharge conditions were used $(5 \mathrm{~mA}, 0.75 \mathrm{kV})$ for the base materials as for the composite materials to enable direct comparison between them. As observed from the depth profile (Fig. 5), the initial concentrations of chromium and nickel in steel were comparable to the bulk concentrations in the steel base material (Table S1). This observation was consistent for both untreated and treated samples. Likewise, the bulk concentration of nickel in the aluminum base material was consistent with its concentration in the aluminum layer for both untreated and treated samples. However, the concentration of chromium in the aluminum layer was more than two orders of magnitude higher than the bulk concentration in the aluminum base material. The values were surprisingly high and therefore were verified by using the complementary technique of EPMA. The EPMA results confirmed a higher chromium concentration in the aluminum layer (Table S2) compared to the bulk concentration in the aluminum base material (Table S1). These EPMA experiments were performed for both treated and untreated samples. The average chromium concentration of $830 \mu \mathrm{g} / \mathrm{g}$ for the treated sample measured by EPMA is comparable to the approximate concentration of $900 \mu \mathrm{g} / \mathrm{g}$ measured from the GDMS depth profile in the aluminum layer. A plausible explanation for the higher chromium content in the aluminum layer is the high diffusion coefficient of chromium in aluminum compared to chromium in steel. ${ }^{32,33}$ Furthermore, it is worth repeating that aluminum is stacked between two steel layers, which may potentially increase the chromium diffusion to aluminum. It is important to stress that the concentrations of both chromium and nickel are slightly higher in the treated sample than in the untreated one, which can be explained through heat treatment of $400^{\circ} \mathrm{C}$ for $30 \mathrm{~min}$. As the untreated sample was also subjected to preheating before the rolling process, and diffusion can occur as a result of exposure to elevated temperatures during the rolling process. Therefore, this is probably why chromium concentration in untreated sample is also high both in depth profile (Fig. 5) and EPMA bulk measurement (Table S2) similar to the treated sample.

Depth resolution. Depth resolution is often used to estimate the ability of analytical techniques to measure local changes of analytes as a function of depth. In general, for GDMS studies, the depth (typically expressed in terms of $\mu \mathrm{m}$ or $\mathrm{nm}$ ) between $16 \%$ and $84 \%$ of analyte concentration is taken as the depth resolution. ${ }^{34}$ The lower the depth resolution, the sharper the transition of changes in the depth profile. In the present study, untreated and treated samples exhibited depth resolutions of about $29 \mu \mathrm{m}$ and $13 \mu \mathrm{m}$, respectively (Fig. 5). For GDMS depth profiling, an edge effect is non-homogenous sputtering of the crater center as compared to the crater edge that contributes to a reduced depth resolution. For the samples investigated in this study, non-homogenous sputtering was greater for the untreated sample than for the treated sample (Fig. 1), contributing to a reduced depth resolution of the untreated sample profile. In addition to the edge effect, the diffusion length of the analytes and the layer thickness also affect the depth resolution. Wang et al. demonstrated that a sample with a film thickness in the range of 4-5 $\mu \mathrm{m}$ resulted in a depth resolution in the range of $0.5-0.7$ $\mu \mathrm{m} .{ }^{35}$ A slow-flow instrument (AutoConcept GD 90) was used in that study, which is similar to the Astrum GDMS in terms of operating parameters and sputtering rates. ${ }^{35}$ Therefore, poor depth resolution is potentially linked to the thickness of the steel layer for the samples used in the present study, which is approximately 80 and $30 \mu \mathrm{m}$ for the treated and untreated samples, respectively (Figs. 2 and 3).

Intermetallic Layer. Enrichment of both the impurity elements of chromium and nickel with two distinct transitions for each element was observed at the interface for both the untreated and treated samples. This can be attributed to the free surface energy at the interface, which leads to the segregation of the impurity elements. The same sample treated at a slightly higher 

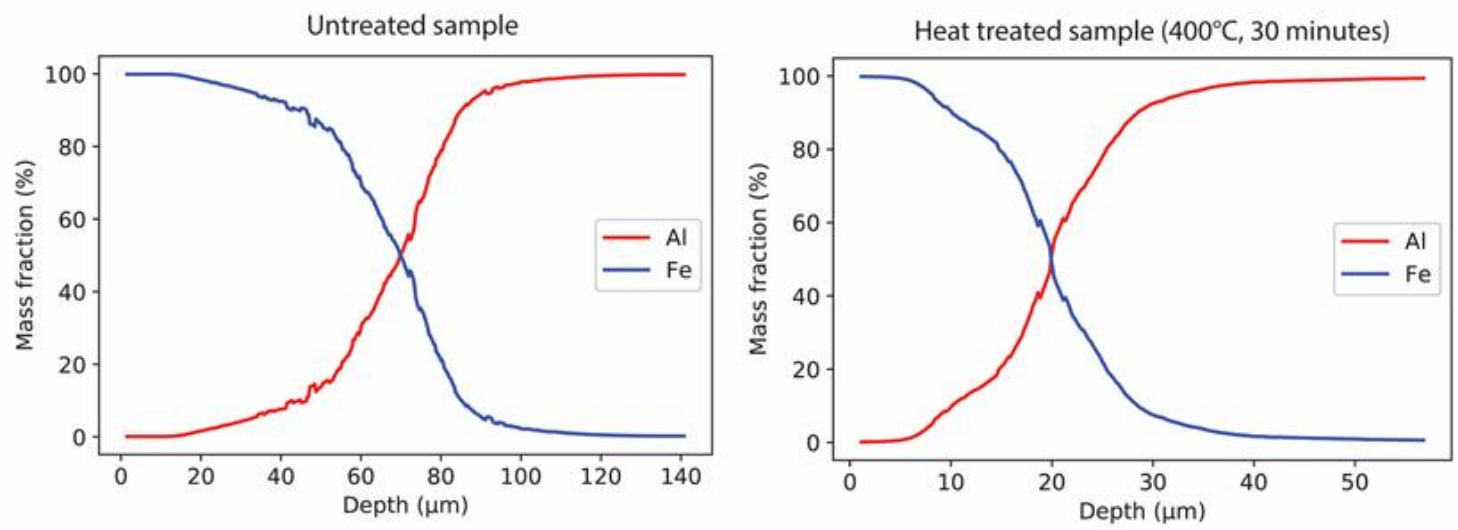

B
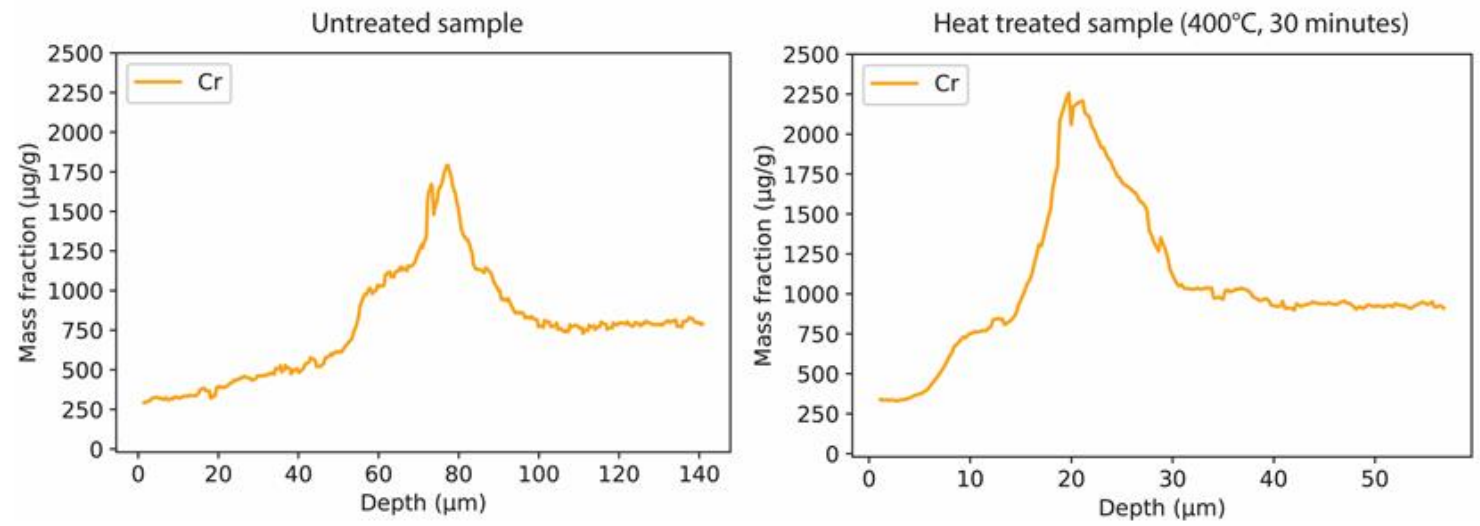

\section{C}
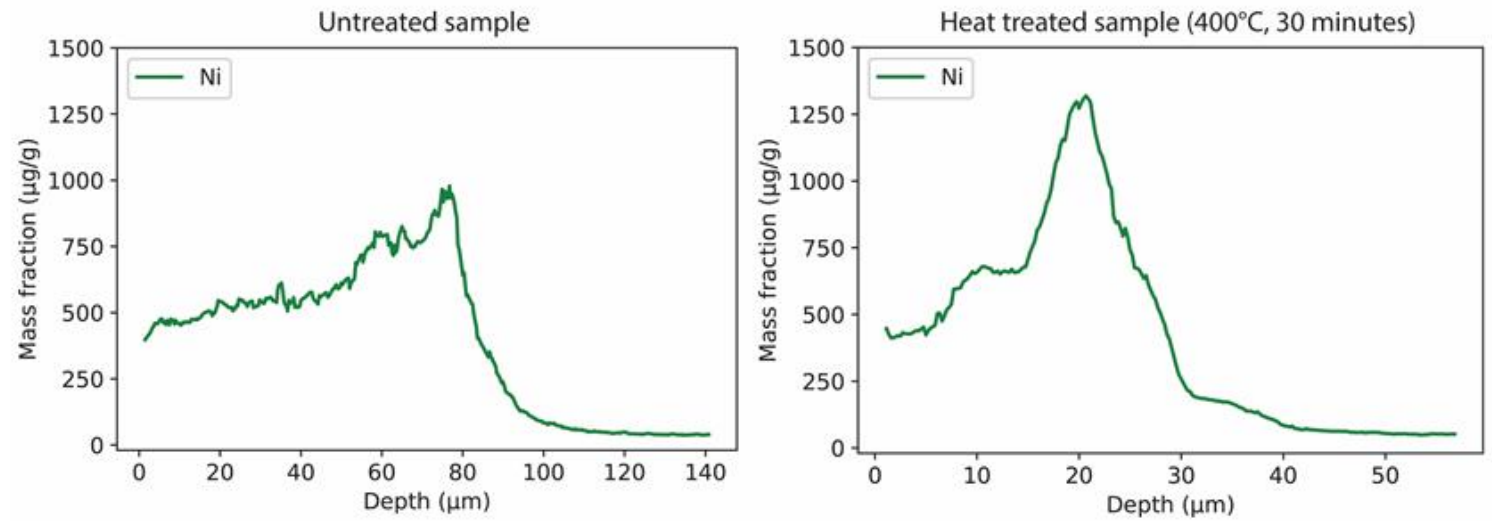

Fig. 5 Depth profile of iron and aluminum (A), chromium (B) and nickel (C) of untreated (left) and treated (right) steel-aluminum composite material after subjecting to discharge condition of $5 \mathrm{~mA}, 0.75 \mathrm{kV}$ using argon flow rates of $0.85 \mathrm{ml} / \mathrm{min}$ and $0.83 \mathrm{ml} / \mathrm{min}$, respectively.

temperature $\left(450^{\circ} \mathrm{C}\right.$ for $\left.2 \mathrm{~h}\right)$ has been shown to result in the formation of two distinct phases within the intermetallic layer (IML): $\mathrm{Fe}_{4} \mathrm{Al}_{13}$ adjacent to the aluminum layer and $\mathrm{Fe}_{2} \mathrm{Al}_{5}$ adjacent to the steel layer. ${ }^{36}$ However, such results were not obtained for the samples used in this study. Since $\mathrm{Fe}_{4} \mathrm{Al}_{13}$ is reported to form prior to $\mathrm{Fe}_{2} \mathrm{Al}_{5}$ at the interface, only one phase might be present after the heat treatment at $400^{\circ} \mathrm{C}$ for $30 \mathrm{~min}$, as shown in Fig. 6. However, the IML formed was too thin to generate EPMA results because of the $1 \mu \mathrm{m}$ electron beam cross-section. In this case, the two peaks (Fig. 5) might correspond to differences in impurity concentrations of nickel and chromium, where the smaller peak is a buildup in the steel material, while the largest peak is the intermetallic layer. Furthermore, the results clearly show that even a small amount of chromium and nickel in the steel base material accumulates at the interface, thereby influencing the IML formation and growth. Previous studies have demonstrated the enrichment of impurities at the interface where steel base materials with higher chromium 

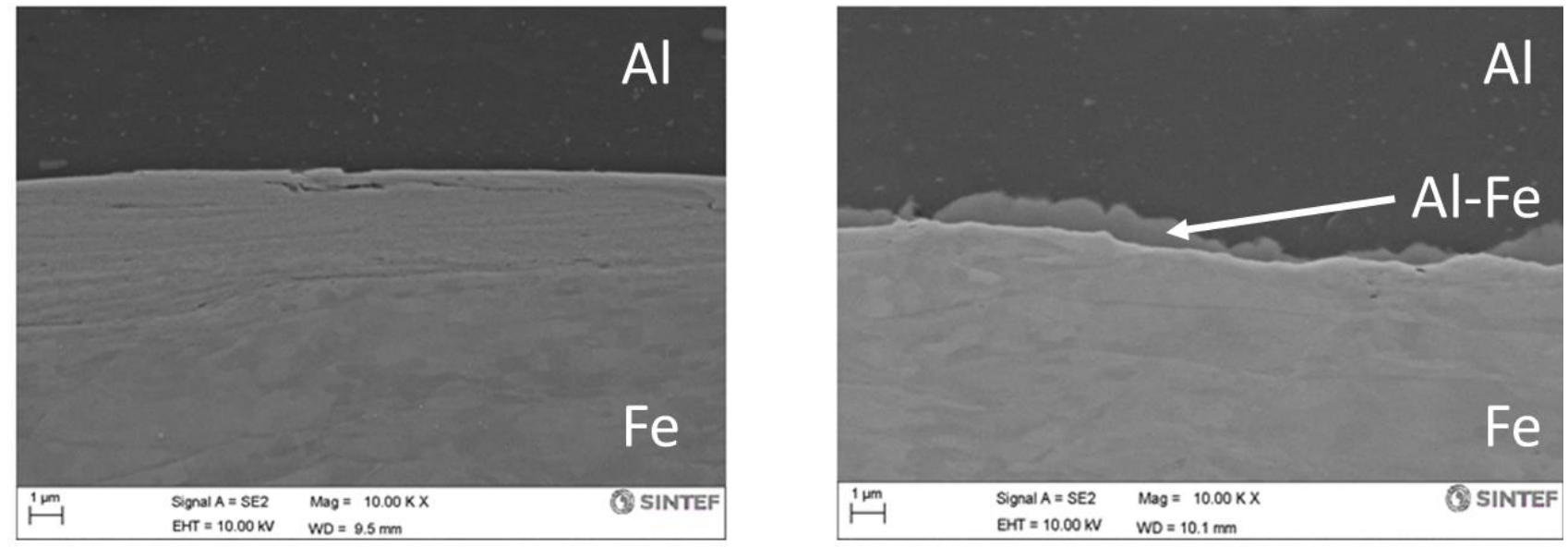

Fig. 6 Scanning electron microscopy images of steel-aluminum untreated (A) and treated (B) samples with dark grey and light grey parts representing the aluminum and steel layers, respectively, with the intermetallic layer at the interface.

and nickel contents were used. ${ }^{5,37}$

Interestingly, the results from SEM and EDS indicate that chromium-iron precipitates were found in the aluminum layer for both treated and untreated samples, indicating diffusion of both chromium and iron into the aluminum layer (Fig. S2 \& Table S3). Previous studies have indicated that diffusion of chromium towards aluminum potentially prevents further migration of iron to the aluminum layer. ${ }^{36}$

\section{CONCLUSIONS}

This study presents the first results of depth profile analysis of a steel-aluminum bilayer using the Astrum GDMS instrument. The slow sputtering rate of the Astrum GDMS posed challenges for metallographic sample preparation, where grinding of the steel layer was required and could not be reproduced. The composite material was treated as a steel layer on top of aluminum, to allow the use of RSFs from a certified aluminum reference material to calibrate the data. The results of the study indicated an enrichment of both chromium and nickel at the steel-aluminum interface, which was higher in the heat-treated sample than in the untreated one. There are valuable findings in this study on the development of thin intermetallic layers caused by the short heat-treatment time, and on the diffusion behavior of chromium. The observation of higher chromium content in the aluminum layer has not been reported in the literature as far as the authors' knowledge. These results increase our knowledge of the mechanisms that govern the formation and growth of intermetallic phases and the influence of alloying elements. This is helpful for optimizing the manufacturing of steel-aluminum joints with regard to the material composition in the joints and the optimal post-joining heat treatment.

\section{ASSOCIATED CONTENT}

Supporting Information. The Supporting Information (Figs. S1-2, Tables S1-3) is available at www.at-spectrosc.com/as/home

\section{AUTHOR INFORMATION}

\section{Corresponding Author}

*G. Paudel

Email address: gagan.paudel@ntnu.no

\section{Notes}

The authors declare no competing financial interest.

\section{ACKNOWLEDGMENT}

The authors are thankful to senior engineer Morten Peder Raanes at the Department of Materials Science and Engineering at NTNU for EPMA analysis. Likewise, the engineers Elin Harboe Albertsen, Anita Storsve and Pei Na Kui from the same department are thanked for continuous support in the laboratory.

\section{REFERENCES}

1. M. M. Atabaki, M. Nikodinovski, P. Chenier, J. Ma, M. Harooni, and R. Kovacevic, J. Manuf. Sci. Prod., 2014, 14. 59-78. https://doi.org/10.1515/jmsp-2014-0007 
2. C. X. Huang, Y. F. Wang, X. L. Ma, S. Yin, H. W. Höppel, M. Göken, X. L. Wu, H. J. Gao, and Y. T. Zhu, Mater. Today, 2018, 21, 713-719. https://doi.org/10.1016/j.mattod.2018.03.006

3. S. M. Arbo, T. Bergh, B. Holmedal, P. E. Vullum, and I. Westermann, Metals, 2019, 9, 827. https://doi.org/10.3390/met9080827

4. S. M. Arbo, T. Bergh, H. Solhaug, I. Westermann, and B. Holmedal, Procedia Manufacturing, 2018, 15, 152-160. https://doi.org/10.1016/j.promfg.2018.07.189

5. V. I. Dybkov, J.. Mater. Sci., 1990, 25, 3615-3633. https://doi.org/10.1007/BF00575397

6. C. L. Lewis, E. S. Oxley, C. K. Pan, R. E. Steiner, and F. L. King, Anal. Chem., 1999, 71, 230-234. https://doi.org/10.1021/ac9806916

7. L. Li, J. T. Millay, J. P. Turner, and F. L. King, J. Am. Soc. Mass Spectrom., 2004, 15, 87-102. https://doi.org/10.1016/j.jasms.2003.09.004

8. E. Oxley, C. Yang, J. Liu, and W. W. Harrison, Anal. Chem., 2003, 75, 6478-6484. https://doi.org/10.1021/ac0346398

9. M. Bouza, R. Pereiro, N. Bordel, A. Sanz-Medel, and B. Fernández, J. Anal. At. Spectrom., 2015, 30, 1108-1116. https://doi.org/10.1039/C4JA00474D

10. N. Tuccitto, L. Lobo, A. Tempez, I. Delfanti, P. Chapon, S. Canulescu, N. Bordel, J. Michler, and A. Licciardello, Rapid Commun. Mass Sp., 2009, 23, 549-556. https://doi.org/10.1002/rcm.3906

11. A. C. Muñiz, J. Pisonero, L. Lobo, C. Gonzalez, N. Bordel, R. Pereiro, A. Tempez, P. Chapon, N. Tuccitto, A. Licciardello, and A. Sanz-Medel, J. Anal. At. Spectrom., 2008, 23, 1239-1246. https://doi.org/10.1039/B804169P

12. J. Pisonero, L. Lobo, N. Bordel, A. Tempez, A. Bensaoula, N. Badi, and A. Sanz-Medel, Sol. Energ. Mat. . Sol. C., 2010, 94, 1352-1357. https://doi.org/10.1016/j.solmat.2010.04.002

13. R. Valledor, J. Pisonero, N. Bordel, J. I. Martín, C. Quirós, A. Tempez, and A. Sanz-Medel, Anal. Bioanal. Chem., 2010, 396, 2881-2887. https://doi.org/10.1007/s00216-009-3382-8

14. J. Pisonero, A. Licciardello, A. Hierro-Rodríguez, C. Quirós, A. Sanz-Medel, and N. Bordel, J. Anal. At. Spectrom., 2011, 26, 1604-1609. https://doi.org/10.1039/C1JA10075K

15. J. Pisonero, R. Valledor, A. Licciardello, C. Quirós, J. I. Martín, A. Sanz-Medel, and N. Bordel, Anal. Bioanal. Chem., 2012, 403, 2437-2448. https://doi.org/10.1007/s00216-011-5601-3

16. A. Alvarez-Toral, P. Sanchez, A. Menéndez, R. Pereiro, A. Sanz-Medel, and B. Fernández, J. Am. Soc. Mass Spectr., 2015, 26, 305-314. https://doi.org/10.1021/jasms.8b04956

17. C. Gonzalez-Gago, J. Pisonero, N. Bordel, A. Sanz-Medel, N. J. Tibbetts, and V. S. Smentkowski, J. Vac. Sci. Technol. A, 2013, 31, 06F106. https://doi.org/10.1116/1.4824164

18. C. González-Gago, J. Pisonero, R. Sandín, J. F. Fuertes, A. Sanz-Medel, and N. Bordel, J. Anal. Atom. Spectro., 2016, 31, 288-296. https://doi.org/10.1039/C5JA00104H
19. V. Bodnar, A. Ganeev, A. Gubal, N. Solovyev, O. Glumov, V. Yakobson, and I. Murin, Spectrochim. Acta B, 2018, 145, 20-28. https://doi.org/10.1016/j.sab.2018.04.002

20. A. Gubal, V. Chuchina, Y. Lyalkin, V. Mikhailovskii, V. Yakobson, N. Solovyev, and A. Ganeev, J. Anal. At. Spectrom., 2020, 35, 1587-1596. https://doi.org/10.1039/D0JA00088D

21. K. Su, X. Wang, and K. Putyera, Yejin Fenxi/Metallurgical Analysis, 2010, Vol 30 Suppl.1, 165.

22. M. Di Sabatino, Measurement, 2014, 50, 135-140. https://doi.org/10.1016/j.measurement.2013.12.024

23. M. Di Sabatino, A. L. Dons, J. Hinrichs, and L. Arnberg, Spectrochim. Acta B, 2011, 66, 144-148. https://doi.org/10.1016/j.sab.2011.01.004

24. M. Di Sabatino, C. Modanese, and L. Arnberg, J. Anal. At. Spectrom., 2014, 29, 2072-2077. https://doi.org/10.1039/C4JA00175C

25. C. Modanese, G. Gaspar, L. Arnberg, and M. Di Sabatino, Anal. Bioanal. Chem., 2014, 406, 7455-7462. https://doi.org/10.1007/s00216-014-8105-0

26. X. Wang, K. Putyera, J. Liu, and D. Leblanc, Distribution Measurements of Dopants in Compensated Silicon Ingots by Fast-Flow High Resolution Glow Discharge Mass Spectrometry. 2011.

27. C. Modanese, M. Di Sabatino, A.-K. Søiland, K. Peter, and L. Arnberg, Prog. Photovolt.: Res. Appl., 2011, 19. 45-53. https://doi.org/10.1002/pip.986

28. C. Modanese, L. Arnberg, and M. Di Sabatino, Mater. Sci. Eng.B-Adv., 2014, 180, 27-32. https://doi.org/10.1016/j.mseb.2013.10.010

29. I. T. Spitsberg and K. Putyera, Surf. Coat. Tech., 2001, 139, 35-43. https://doi.org/10.1016/S0257-8972(00)01162-2

30. L. M. He, J. D. Meyer, W. Y. Lee, K. Putyera, and L. R. Walker, Metall. Mater. Trans. A, 2002, 33, 3578-3582. https://doi.org/10.1007/s11661-002-0348-2

31. A. Bogaerts, W. Verscharen, and E. Steers, Spectrochim. Acta B, 2004, 59, 1403-1411. https://doi.org/10.1016/j.sab.2004.06.005

32. Y. Du, Y. A. Chang, B. Y. Huang, W. P. Gong, Z. P. Jin, H. H. Xu, Z. H. Yuan, Y. Liu, Y. H. He, and F. Y. Xie, Mater. Sci. Eng.A-Struct., 2003, 363, 140-151. https://doi.org/10.1016/S0921-5093(03)00624-5

33. R. Braun and M. Feller-Kniepmeier, Phys. Status solidi (a), 1985, 90, 553-561. https://doi.org/10.1002/pssa.2210900219

34. A. Raith, R. C. Hutton, and J. C. Huneke, J. Anal. At. Spectrom., 1993, 8, 867-873. https://doi.org/10.1039/JA9930800867

35. M. L. Wang, B. Zhuo, S. J. Zhuo, Y. Q. Zhu, L. Huang, and R. Qian, At. Spectrosc., 2021, 42, 183-189. https://doi.org/10.46770/AS.2021.070

36. S. M. Arbo. Cold welding of steel and aluminum alloys - Joining processes, intermetallic phases and bond strength. Norwegian University of Science and Technology, Trondheim, 2020.

37. Y. X. Li, Q. Jia, Z. T. Zhu, W. Gao, and H. Chen, Surf. Rev. Lett., 2017, 24, 1750046. https://doi.org/10.1142/s0218625x17500469 